\title{
Review of DC Offset Compensation Techniques for Grid Connected Inverters
}

\author{
Ahmed Omar ${ }^{1}$, Adel El-Rfaey ${ }^{2}$, Mona Fouad Moussa ${ }^{3}$, Yasser Gaber Dessouky ${ }^{4}$ \\ Department of Electrical Engineering, Arab Academy for Science, Technology and Maritime Transport, Egypt
}

\begin{tabular}{l} 
Article Info \\
\hline Article history: \\
Received Dec 16, 2017 \\
Revised Jan 18, 2018 \\
Accepted Feb 2, 2018 \\
\hline
\end{tabular}

\section{Keyword:}

DC offset compensation techniques

Grid connected inverters

\begin{abstract}
Limitations of DC injection into the AC network is an important operational requirement for grid connected photovoltaic systems. There is one way to ensure that this issue needs a power transformer as a connection to the AC network. However, this solution adds cost, volume, mass, and power losses. Ideally there shouldn't be any DC at the output of the inverter, but practically, a small amount of DC current is present. Therefore, in this paper there are techniques for the DC offset elimination are proposed. Some have drawbacks which was treated by another technique. Also there are best solutions for eliminating DC offset as in section 17, and 18 as it explains how to reduce the DC offset in a transformerless operation with reducing the power losses, mass and the cost effect..
\end{abstract}

Copyright $\odot 2018$ Institute of Advanced Engineering and Science. All rights reserved.

\section{Corresponding Author:}

Ahmed Omar,

Department of Electrical Engineering,

Arab Academy for Science, Technology and Maritime Transport,

Alexandria Desert Rd, Giza Governorate, Egypt.

Email: ahmedomr_eg@hotmail.com

\section{INTRODUCTION}

Power quality is an essential issue for the combination of grid connected inverters. The issues identified to DC current injection in inverter based distributed generation have been generally overlooked, in spite of developing concerns regarding its impact on distribution system components. One of the most extreme issues brought on by DC current injection is saturation of the distribution transformers bringing about waveform distortion, excessive losses, overheating and dimensioned life expectancy. In addition, it also may cause mistakes in some of the measurement and protective relays systems [1].

An acceptable source of DC current injection into the grid emerges from the semiconductor circuits in inverter frameworks. The presence of undesirable DC current components in the output currents of such frameworks can be ascribed to several factors such as pulse width modulation signals, non-linearity of the switching devices, and the drift in the voltage and current measurement sensors used to give feedback signals for the control frameworks. A number of rules and standards are forced to limit the effect of DC current injection into the grid [2], [3]. Among these principles and proposals are rules to restrain the allowable amount of DC current injection into the distribution network. They vary from country to country. For instance, British standard limits DC injection to $20 \mathrm{~mA}$ for distributed generation with stage streams beneath $16 \mathrm{~A}_{\mathrm{rms}}$ [4]. In IEEE standard 'IEEE 929-2000' the DC limits is $0.5 \%$ of the inverter rated current [5].

The DC current injection in the Australian standard AS4777.2 should not exceed $0.5 \%$ of the inverter rated output current or 5mA, which is the greater [6]. Various methods have been proposed to prevent or minimize DC current injection by grid-connected inverters in photovoltaic systems. This paper presents a review on the issue of the DC offset and how to overcome it with different methods through existing techniques that have been submitted to limit DC current injection into the distribution network as will be illustrated in each section. section 1 is the Introduction, section 2 presents the isolation transformer 
method for minimizing the DC offset, section 3 presents the capacitors method for DC offset, section 4 presents the voltage transformer method to limit the DC offset, section 5 proposes the low power transformer method, section 6 discusses the current transducer method, section 7 explains the DC current sensors, section 8 presents the power interfacing transformer method, section 9 proposes the mathematical model method for the DC offset, section 10 talks about the new compensation circuit method, section 11 gives a brief about the AC-coupling method, section 12 proposes the DC offset compensated voltage buffer method, section 13 presents the differential amplifier method, section 14 talks about the feedback system technique, section 15 proposes a new approach of for DC link current sensors, section 16 talks about the DC current measurement in inverter output, in section 17 the authors present a novel control strategy for reduction of DC offset, section 18 shows the transformerless method for suppression of DC offset, and section 19 is the conclusion.

\section{ISOLATION TRANSFORMER}

The authors present A line frequency isolation transformer which is frequently employed at the inverter to prevent penetration of unwanted DC currents into the grid. Also, it provides galvanic isolation between the photovoltaic system and the grid. However, a 50/60 Hz transformer is large, heavy and is a substantial cost in grid connected inverter systems. Additionally, it contributes to system losses and footprint. Thus, transformerless system has become attractive in the recent years. It has been claimed that adoption of a transformer less PV inverter system reduces the overall system costs by $25 \%$ compared to the cost of a system that includes a transformer [7] and improves system efficiency about 1.5 to $2 \%$ [8]. So this technique has several drawbacks as the cost, system losses due to the transformer that lead us to use other technique without transformer such as the use of capacitors in section 3 .

\section{CAPACITORS}

The author presents here that The use of capacitors either it is AC or DC for preventing DC current injection into the grid. There are some approaches using AC or DC capacitors, we will illustrate some of them. First one gives a single-phase half-bridge inverter with DC capacitors. DC node formed from the connection of two DC capacitors in series [9], [10]. It is noted that this approach is not extended to threephase inverters as shown in Figure.1. Second one that doesn't allow DC current injection into the grid by putting an AC capacitor in series with the grid [11]. Figure 2 illustrates that there are series diodes connected across the capacitor to prevent over voltage protection. This method better than that of the isolation transformer but also has some limitations as it can't be used for three phase inverter. So we go through another point of view as the voltage transformer.

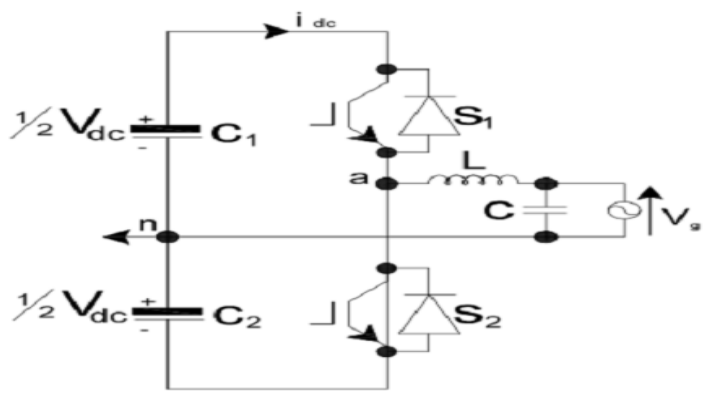

Figure 1. Single phase half bridge inverter with DC capacitors

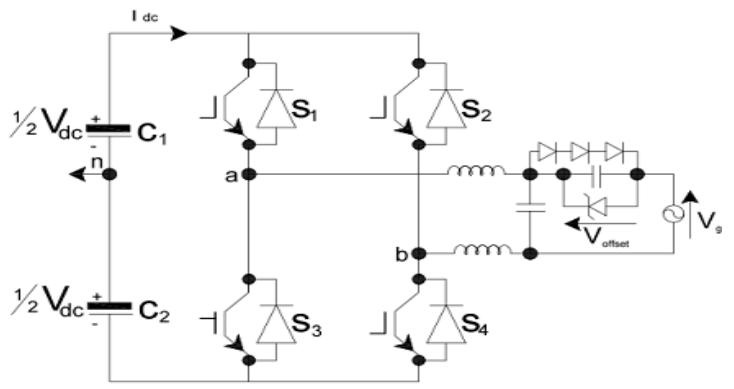

Figure 2. Single phase H-bridge inverter with AC capacitor

\section{VOLTAGE TRANSFORMER}

The authors explain Active methods that are used for preventing DC current injection into the grid based on current sensors in contact with voltage transformer (VT) to limit DC injection, although the current sensor is expensive in detecting small DC component. It talks about a voltage transformer with 1:1 turn's ratio, and $\mathrm{RC}$ circuit. The primary side of the voltage transformer is connected across the grid while the secondary one is connected in series with the RC circuit as illustrated in Figure 3 The DC current is limited by the feedback of the proportional integral controller which adjusts the inverter current by this conventional controller. This method is expensive as it requires complex transformers and current sensors so it adds cost and power loss [12]. This technique limits the small DC component as possible at it can but it is too 
expensive as it is not only use the voltage transformer which costs too much but also current sensors. Hence, we will use a power transformer as a DC offset sensor in the following section.

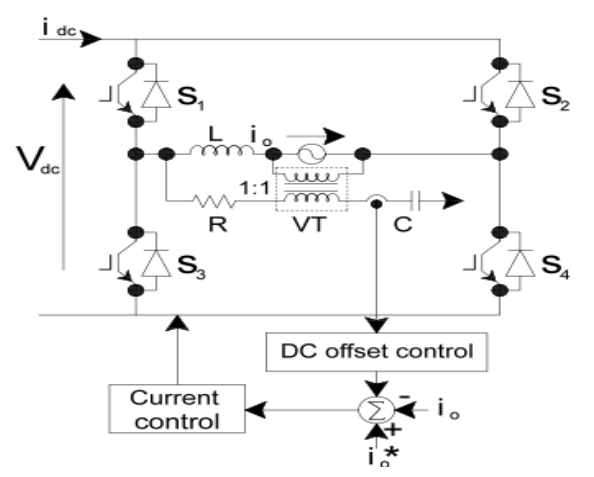

Figure 3. DC offset current control loop with a voltage transformer

\section{LOW POWER TRANSFORMER}

The authors illustrate technique about DC compensation using low power transformer as a DC offset sensor. A DC sensor is connected across the inverter terminals and consists of a magnetic circuit which is applicable by using low power transformer as illustrated in Fig. 4 When a DC voltage appears at the inverter output in a closed loop condition, there is a big distortion results in the reactor current. The results approve that this technique is able to minimize the DC current component [13]. However, it also contains the power transformer which will to increase the cost. We move through the next section which discusses the current transducer in detecting and removing the DC component from the system.

\section{CURRENT TRANSDUCER}

This method was discussed by the authors as the current transducer which is emplaced between DC capacitor and inverter switches as illustrated in Fig.5 to measure the current which is drawn from the output. There are two states for connection for the operation of the inverter, initial one is the connecting state which happened when the output current streams to the load through the DC connect sensor, and the second one is the freewheeling state where the current sensor output can be utilized to expel the offset current accessible in the inverter current. Notwithstanding this favorable position this procedure has the ability to operate without transformer so it reduces the cost [10]. This method is better than before, as the current sensor output can be used to remove any DC offset found in the inverter output current in a transformerless operation so it reduces the cost. However, the authors showed experimental results prove that the elimination of the DC component in this method is limited within certain range. Hence we go through another technique as the two DC join current sensors in section 7 .

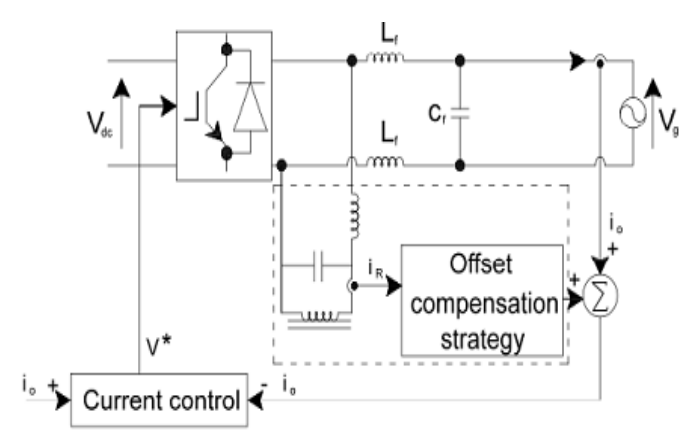

Figure 4. DC compensation technique using low power transformer as a DC offset sensor

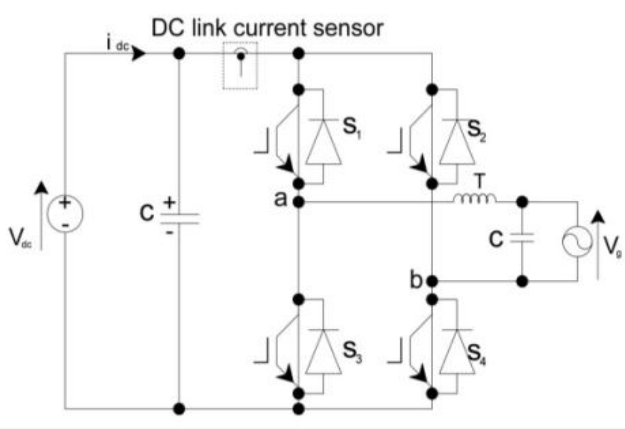

Figure 5. H-bridge inverter using DC-link current sensor to compensate DC current injection into the grid 


\section{DC CURRENT SENSORS}

The authors Examine two DC join current sensors are utilized to remunerate the DC offset current in the three-level half-bridge inverter as delineated in Fig. 6 the upper sensor is associated between the upper terminal of capacitor $C_{1}$ and the upper switch $S_{1}$ to quantify the positive DC link current during the positive portion of the main cycle. The DC offset is aligned during the negative half cycle, when the positive DC link current drops to zero. The lower sensor is coupled between the base terminal of DC capacitor $\mathrm{C}_{2}$ and switch $\mathrm{S}_{4}$ to gauge the negative DC link current during the negative half cycle. For this situation, the DC offset is expelled during the positive half cycle when the negative DC interface drops to zero during the positive half mains cycle.

However, the guaranteed achievement of this technique is limited because the present sensors are set where they measure discontinuous currents, which is illogical [10]. This technique uses two DC join current sensors not only which played the role of the power transformer as in section 5 so it allows the transformerless operation, but it has a big disadvantage that it measures the discontinuous current which is impractical.

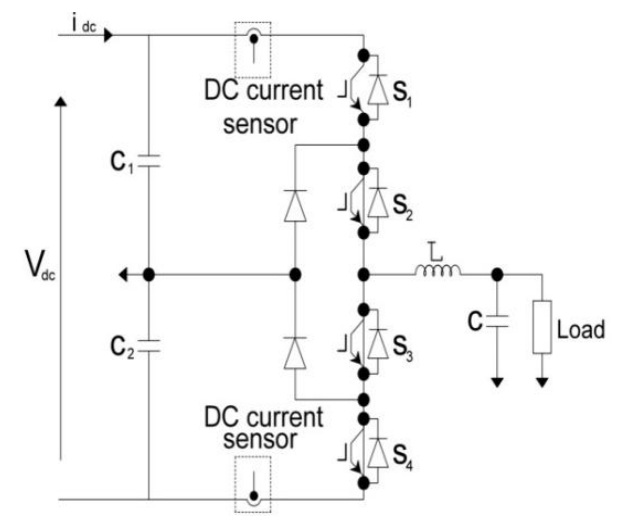

Figure 6. Three-level half bridge inverter using positive and negative DC current sensors to compensate DC current injection to the load

\section{POWER INTERFACING TRANSFORMER}

The authors Present the limitation of the DC injection into AC network by grid connected inverters. This procedure is made by using a power transformer as an interface between the output of the inverter and the AC network. This technique has some serious disadvantages, ideally no DC current can be available at the output of the inverter, but practically in the absence of some special measures, a little amount of DC is available as a result of circuit component imperfections. The focus of this technique is on the mathematical modeling of a proposed DC offset sensor and DC offset control system. The disadvantages of this technique are power losses and it adds costs, mass and volume. DC power from the solar panel is changed to AC by an inverter. Theoretically the output current of the inverter should be purely AC, but practically it will contain small amount of DC. As the DC injection increase in the AC network, this can result in troubles as transformer saturation, transformer magnetizing current distortion, metering errors, and malfunction of protective equipment. For this causes there are some standards that put limits for DC injection [14]. As illustrated in this technique has several drawbacks, this lead us to use another method in the next sections.

\section{MATHEMATICAL MODEL}

The authors demonstrate alternative solutions for the DC injection trouble that has been introduced: It provides the usage of a feedback loop to eliminate the DC offset. A simple mathematical model is enhanced for the feedback system. It is proposed that the inverter is voltage controlled. But there is no experimentation validated for this technique. Offset current is due to circuit component imperfections. With the DC offset controller operating, a compensating current $i_{c}$ is produced at steady state, which theoretically cancels offset current[14].

The control system received for the DC bus voltage is shown in Fig. 8 Effective control of the DC bus voltage guarantees balance between power output of the DC to DC converter and power injected into the AC network. A basic corresponding controller with gain $K_{p}$ is utilized. The DC bus voltage signal is weakened by a factor $K_{d}$ and filtered. At steady state the output of the corresponding control will be a 
constant value. This is multiplied by a sinusoidal signal which is in phase with AC supply voltage $v_{s}$. There is an output of the multiplier, $k_{h} i_{s r}$ is the current reference for the inverter. An increase in the output power from the solar panels will affect the DC bus voltage $V_{d c}$ to increase consequently. This makes the error voltage at the input of the corresponding controller to increase which lead to an increase in the inverter current reference signal. So the output current of the inverter goes up and more power is sustained into the AC network. Eventually, a rise in power output from the solar panels leads to expansion for the DC bus voltage steady state error [14]. This technique is perfect mathematically at it provides the issue with a feedback system through a mathematical model, but there are no experimental results validate this technique. Hence, a new method is presented in section $\mathrm{X}$.

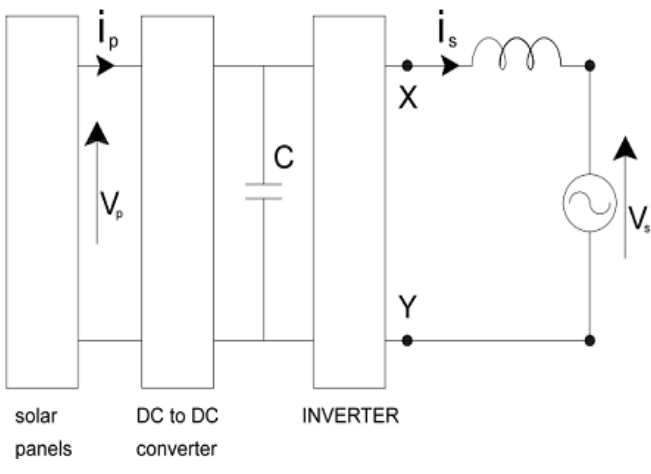

Figure 7. Grid-Connected PV System

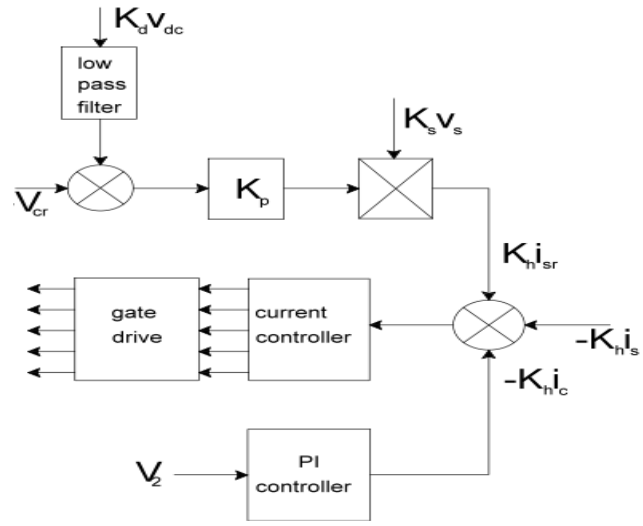

Figure 8. Inverter Control System

Whichi $\mathrm{i}_{\mathrm{c}}$ compensating current, $\mathrm{i}_{\mathrm{sr}}$ reference current, $\mathrm{i}_{\mathrm{s}}$ offset current, $k_{e}$ PI controller gain, $k_{h}$ hall effect constant=1V/A, $v_{d c}$ DC bus voltage.

\section{NEW COMPENSATION CIRCUIT}

The authors clarify a new current detecting method for the current-mode DC-DC buck converter, however the current mirroring scheme helps to prevent conversion efficiency from decreasing, and it endures from the voltage offset of the amplifier feedback. So this approach proposes a new compensation circuit involved into the current sensing block to overcome the offset voltage [15]. The integration of a system into single chip is successively figured out nowadays, different structure topics should know for SOC (SystemOn-Chip) implementations [16], [17]. For attaining the challenging hardware, the integrated circuits as DCDC converters are involved into a chip as mixed-signal circuits in addition to digital processing system [18], [19].

The general block diagram of the current mode DC-DC buck converter is appeared in Fig. 9. The inductor and capacitor have a usage in the output filter. The PMOS and NMOS switches are controlled by the $\mathrm{ON}$ and OFF time signals. That is characterized by the duty cycle of the PWM (Pulse-Width Modulation) signal generator. Amid the ON time the PMOS draws the current from the battery and supply the inductor with the current which renews the output capacitor. This capacitor has a great usage in keeping up the output voltage during providing the output load current $I_{l}$. Beside that the feedback sensing of the current.

In the current-mode DC-DC converter, the current flowing through the inductor can be used for controlling the converter operations and accordingly producing the corresponding PWM signals for the output switches. The ordinary approach to detect the current flowing through the inductor is to put the resistor along the current path and screen the voltage drop over the resistor [20], [21]. Its value ought to be very small in order not to corrupt the conversion efficiency in light of the fact that the conduction loss of the converter fundamentally comes from energy scattering due to the resistive component along the current path. Beside that the current of the inductor will be sufficiently increased for the instance of large duty cycle operation. Current mirroring between the output switch and sensing transistors can be used to screen the current which flows across the inductor. The operating points should be identical between the two transistors by using the feedback loop. 


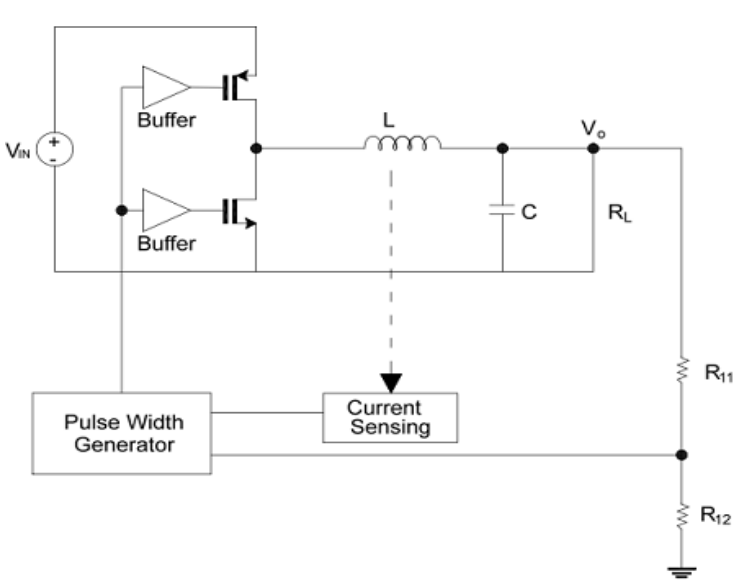

Figure 9. Block diagram of the current-mode DC-DC buck converter

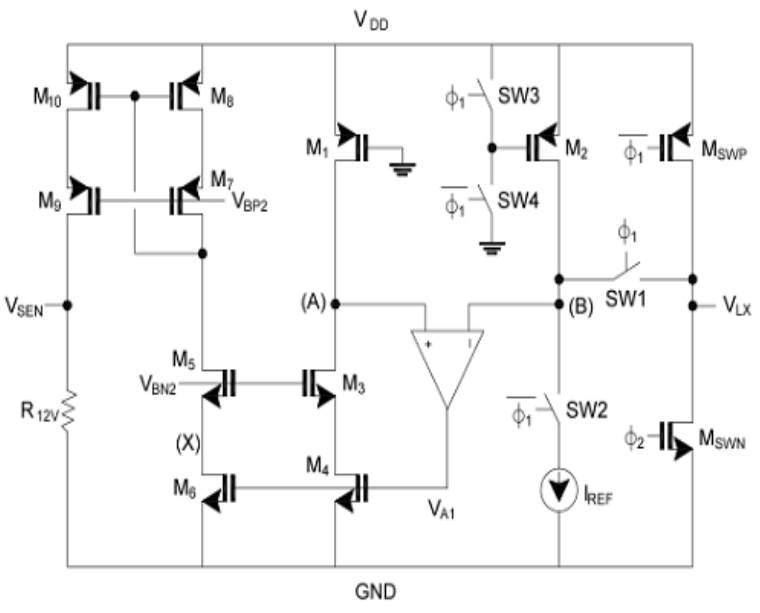

Figure 10. Circuit schematic of the current-sensing operation

The current sensing circuit which will be proposed, the sensed current in it is divided into small bias current and sensed current that will be changed into voltage signal. In Figure 10 there are twelve transistors $\left(M_{1}, M_{2}, M_{3}, M_{4}, M_{5}, M_{6}, M_{7}, M_{8}, M_{9}, M_{10}, M_{s w p}, M_{s w n}\right)$, four switches (SW1, SW2, SW3, SW4), one resistor and $A_{1}$ which is an amplifier. In this circuit transistor $M_{4}$ derived by the output of the feedback amplifier $A_{1}$ in order to make the sensed current of transistor $M_{1}$ flows in $M_{4}$ that will enhance the accuracy of sensing. The two transistors $M_{\text {swp }}$ and $M_{\text {swn }}$ are the output switches that are derived by the ON-time which is given the symbol $\Phi_{1}$ and the OFF-time which is given the symbol $\Phi_{2}$, separately. If the feedback is negative by the amplifier, it will lead the nodes of (A) and (B) typical in order to make the current connecting between $\mathrm{M}_{1}$ and $\mathrm{M}_{2}$ can be accomplished because of the similarity of the source-drain voltages.

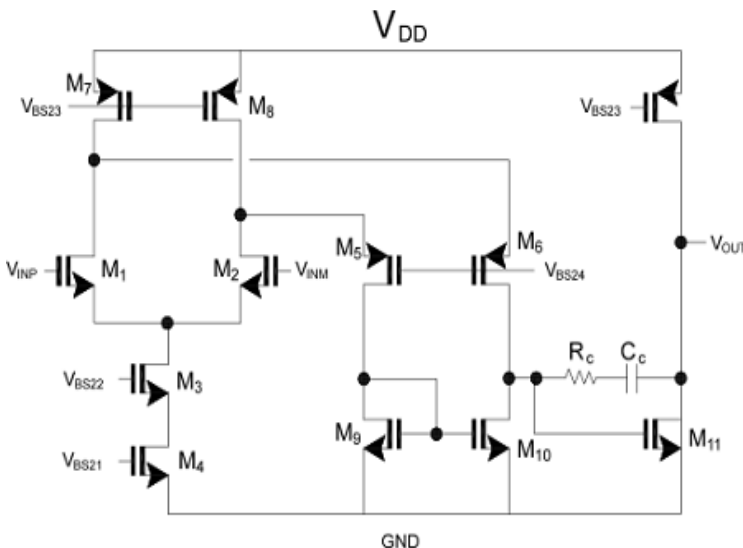

Figure 11. Circuit schematic of the operational amplifier

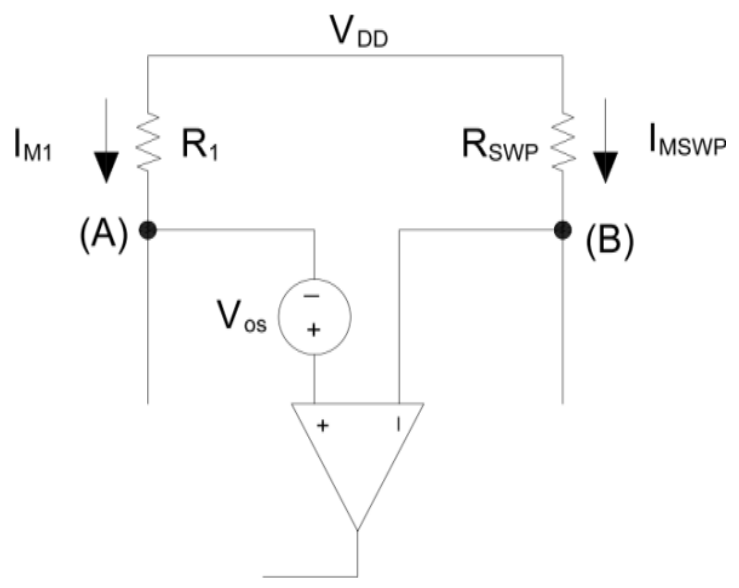

Figure 12. Operational amplifier including the offset voltage during $\Phi_{1}$

The voltage offset of the CMOS operational amplifier may be sufficiently large in order to break down the error in the configuration of the closed loop. Figure 12 illustrates the operational amplifier which was found in the current sensing circuit that is shown in Figure 11 with the offset voltage during ON-time when $\Phi_{1}$ is high. The offset voltage of the operational amplifier should be sufficiently large so that the error causes damage to the closed loop configuration. Figure 12 shows the operational amplifier included in the current sensing circuit of Figure 11 with the voltage offset that is maintained during the ON-time when $\Phi_{1}$ is high. $R_{1}$ and $R_{S W P}$ are the equivalent resistances of transistors $M_{1}$ and $M_{S W P}$. 
The current of the inductor is detected while the ON-time $\left(\Phi_{1}\right)$, the output voltage $\mathrm{V}_{\mathrm{SEN} 2}$ while OFFtime should be used for compensating the voltage offset of the amplifier. By the next $\Phi_{1}$ of ON-time, the integration happens also the control voltage identify the current which flows through transistor $\mathrm{M}_{\mathrm{C}}$. This output current can be utilized for compensating the offset voltage. Since the loop of compensation in Figure 13 contains the integrator, a huge DC gain could be sufficient to decrease the error which was found in the operation of the closed loop. The capacitance proportion of the integrator and the clock frequency decide the settling time of offset compensation operation. This operation amplifier has low power-consumption caused limitation for the amplifier bandwidth and a huge error could occur while integration when the DC-DC converter works with low duty cycle. In spite of all of these drawbacks the compensation of the offset voltage continues working [22]. This approach has a compensation circuit to overcome the offset voltage found in the amplifier feedback. But it has a problem that the voltage drop across the resistor might be not small and can cause a corruption for the conversion efficiency in case of the fact that the conduction loss of the converter comes from energy scattering due to the resistive component along the current path.

\section{AC-COUPLING METHOD}

A new technique is proposed by the author for DC-offset removal, in integrated wireless receivers as DCRs (direct-conversion receivers) which use bandwidth efficient modulation schemes as QAM (quadrature amplitude modulation), DC-offset is a big issue which faces these receivers, so if it remains as it is without any compensation, it can cause damage to the overall system performance. There is a solution here which can eliminate this DC-offset by using AC-coupling to eliminate the low-frequency disturbances [23]. DCR has the RF (radio frequency) signal which is changed to zero frequency and in sequence of that the DC-offset will cause errors to the signal [24], [25], [26].

The DC-offset can eliminate the receiver performance as said before. By putting first-order ACcoupling high pass filter, in the in-phase and quadrature signal paths, as illustrated in Figure 14, that eliminate the results of DC-offset. But also it can make a big reduction in performance if the usage of the baseband of the signal spectrum of the modulation scheme has energy near DC [26]. This is applied if the QAM scheme is used. BPF (band path filter), LNA (low-noise amplifier). As illustrated in this section that The AC-coupling high pass filter can eliminate the DC component. Although, it has a drawback which results in a big reduction in performance if the usage of the baseband of the spectrum has energy near DC. This technique was skipped for its drawbacks and move through the following technique.

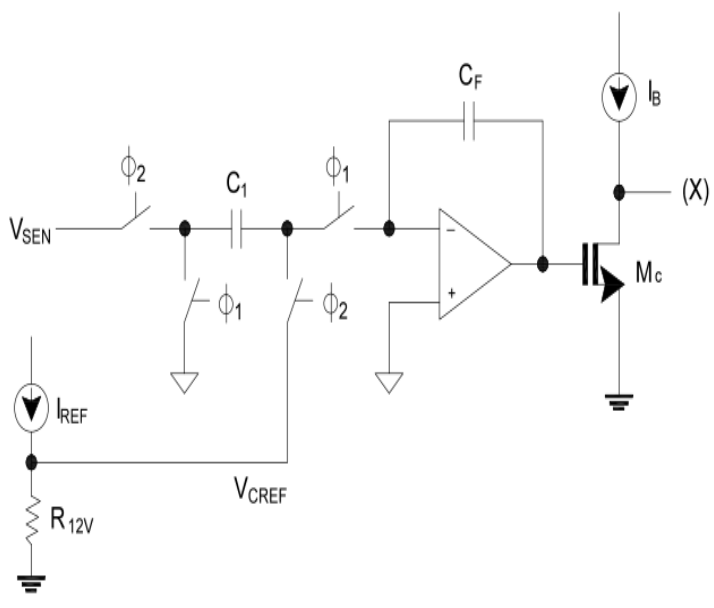

Figure 13. Proposed scheme to compensate the offset voltage of the amplifier

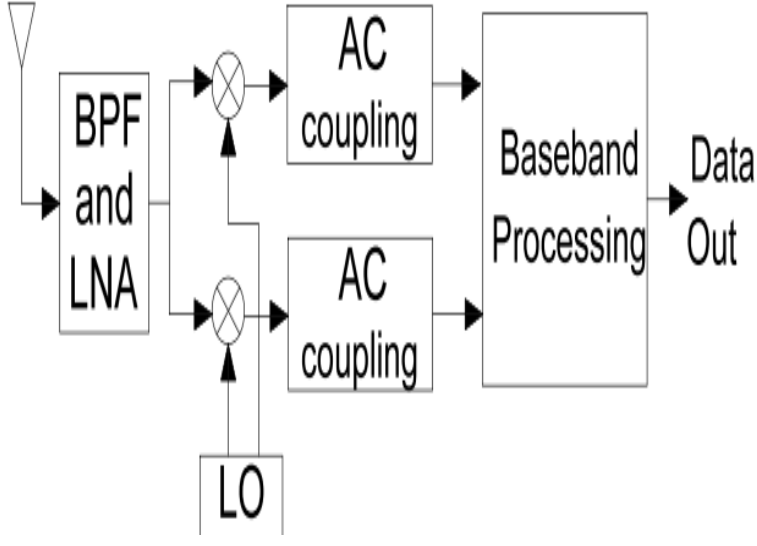

Figure 14. A direct-conversion receiver with ACcoupling

\section{DC OFFSET COMPENSATED VOLTAGE BUFFER}

The author shows a new DC offset compensation technique for voltage buffers. It can be utilized to enhance the accuracy of data converters. That technique decreases the error of the gain of the operation amplifier [27]. The request for more resolution and much more speed DAC's (digital analogue converters) is extended every year with the demand electronics applications. The performance of DACs could be enhanced by using offset compensation techniques. Probably a large part of the conventional techniques compensates 
only for the DC offset voltage of the operation amplifier but not the error of the gain [28]. There is a need for reset operation amplifier output to zero at every cycle, so this approach proposes a DC offset compensation technique which compensates for offset voltage and error of the gain of the operation amplifier.

This circuit as other exchanged capacitor circuits endures from channel charge injection which can be limited by turning $S_{1}$ off somewhat before $S_{3}$, when $S_{1}$ is turned off, charge (which is the element of the voltage at node $\mathrm{X}$ ) is infused onto the capacitor and this charge shows up a constant offset at the output. After $\mathrm{S}_{1}$ is off, the total charge at node $\mathrm{X}$ stay constant making the circuit away from the charge infusion of $\mathrm{S}_{3}$ or charge absorption of $S_{2}$. The circuit is quick as the transition of the voltage at the output node is small enough, however the conventional circuits of the offset compensation are decelerating because of the large transients of the voltage at the output [28].

The proposed DC offset compensated voltage buffer shown in Figure 15 is implemented using three switches $S_{1}, S_{2}$ and $S_{3}$ and a capacitor $C$. The performance of the circuit like other switched capacitor circuits brooks from the charge injection of the channel which can be reduced by opening $S_{1}$ slowly before $S_{3}$. When $\mathrm{S}_{1}$ opened, the charge is going to the capacitor $\mathrm{C}$ and this charge is found as an offset at the output.

When $S_{1}$ is off, the total charge stays constant as it is which will lead the circuit insensitive for charging injection to $S_{3}$ or the charging absorption for $S_{2}[28]$.

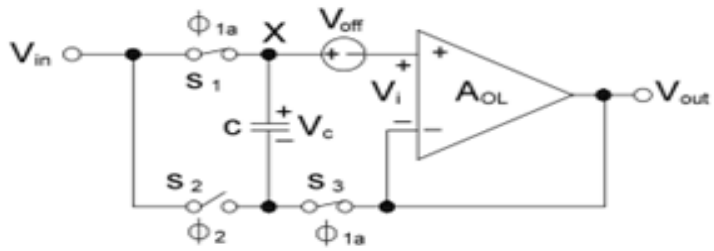

(a)

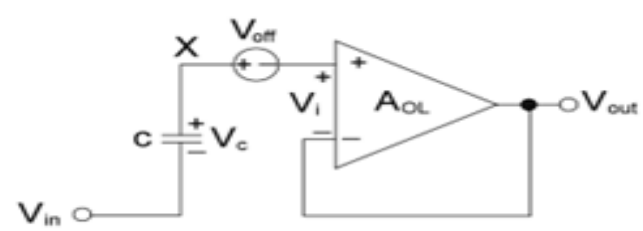

(c)

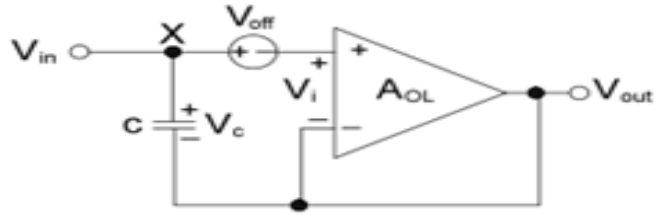

(b)

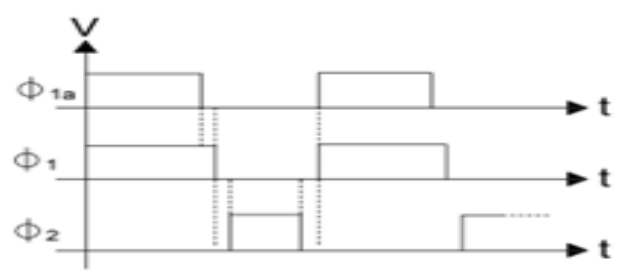

(d)

Figure 15. (a) New DC offset compensated voltage buffer, , (b) circuit during phase-1, (c) circuit during phase-2, (d) clocks $\square_{1}, \square_{1}, \square_{2}$.applied to the switches $S_{1}, S_{2}$, and $S_{3}$ respectively

The conventional offset compensation circuits have a low speed due to big transients in the output. From the above section we get that this method not only overcome the DC offset but also it improves the accuracy of the data converters and decreases the error of the gain in the operational amplifier. Although it has a big disadvantage that the conventional circuits of the offset compensation are decelerate because of the large transients of the voltage at the output of the operational amplifier. This drawback let us try to find a new solution better than that in the following sections.

\section{DIFFERENTIAL AMPLIFIER}

This technique was introduced by the author which give a brief about the DC offset which is already known as before, as the excessive injection of DC into AC can prompt issues such as corrosion in underground equipment [29], transformer magnetizing current distortion and transformer saturation [30] and failure in the function of the protective equipment [31]. In this manner rules and measures have been set up to control the DC injection [32]. Australian Standard AS4777.2 limits the DC injection to $5 \mathrm{~mA}$ or $0.5 \%$ of the rated output as illustrated before in the introduction, while in the United Kingdom, ER G83/1 put a limit of $20 \mathrm{~mA}[33]$.

There was a suggestion can be applied using a voltage sensor at the inverter output contains the differential amplifier and a low pass filter. Hence, any DC component is detected at the output of the low pass filter which returns back to the controller that makes the inverter eliminates the DC offset and there was 
a mathematical model for that control system [33]. It seems that this method has a big similarity to the technique which was explained in section 9, so there are no experimental results validate this technique.

\section{FEEDBACK SYSTEM}

The simplest way to eliminate DC injection is to keep a grid frequency transformer. That is the solution adjusted in a number of commercial systems [34], [35]. The measurements of DC currents from the AC output of commercial systems are also proposed in [35]. There are number of system configurations that have been presented for single-phase grid connected PV systems [36]. The configuration that has been used and was introduced by the author to get the DC offset elimination method which is shown in Figure 16.

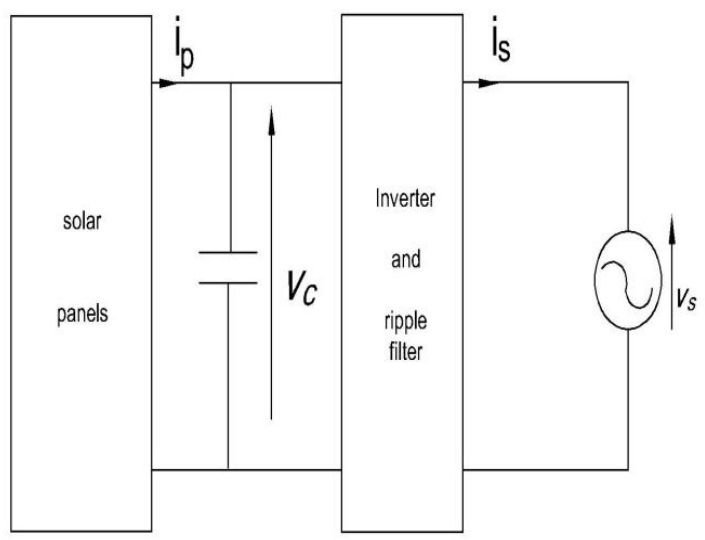

Figure 16. Grid connected PV system

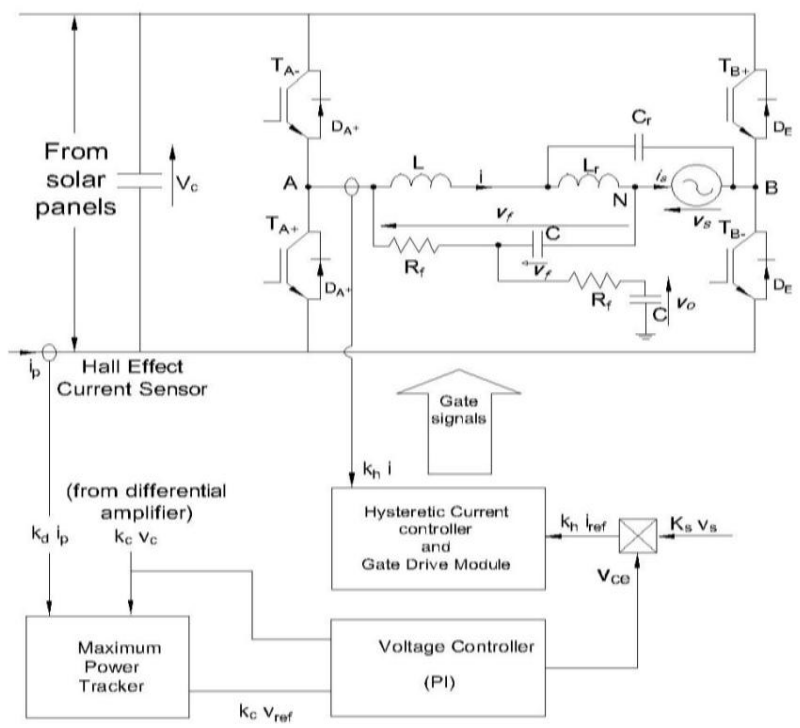

Figure 17. Inverter main components and DC-offset sensor

The main components of the inverter are shown in Figure 17. The unity power factor used for reference current $i_{r e f}$ for the hysteresis current controller[36],[37]. is coordinated to be in phase with the AC supply voltage $v_{s}$. During the positive half cycle of the source voltage, insulated gate bipolar transistor $\mathrm{T}_{\mathrm{B}+}$ is kept off and $\mathrm{T}_{\mathrm{B}-}$ is kept on. Transistor $\mathrm{T}_{\mathrm{A}+}$ is turned on when the current of the inverter output $(i)$ goes below the bottom standard of the hysteretic band. This leads $i$ to rise while it flows through $\mathrm{T}_{\mathrm{A}+}$ and $\mathrm{T}_{\mathrm{B}-\text { - }}$ When current $i$ exceeds the upper limit of the band $\mathrm{T}_{\mathrm{A}+}$ is switched off. This leads $i$ to fall when flowing through

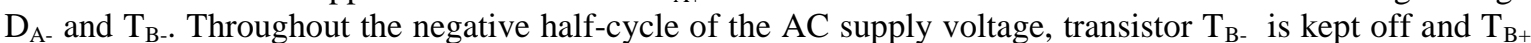

Int J Pow Elec \& Dri Syst, Vol. 9, No. 2, June 2018 : 478 - 494 
is kept on. Transistor $\mathrm{T}_{\mathrm{A} \text { - }}$ is switched on when the current of the inverter output $(i)$ goes above the top limit of the hysteretic band[38]. There is no substantial storage between the solar panel output and the inverter output. If the isolation level falls or rises, the root mean square (rms) value should rise or fall depend on the isolation level. In sequence of that the power balance will be protected. It is the role of the voltage control loop to keep balance between the DC output of the PV panel and the output of the inverter in the AC network. A rise in the output power from the solar panels makes an increase in the DC bus voltage which will make a rise in the $V_{C C}$. This will lead the rms value of the $I_{r e f}$ to increase resulting in the rms of the inverter output current $I_{S}$ as it follows $I_{r e f}$. The rise in the inverter output current stores back the balance of the power between the DC output power of the PV panels and the AC output power of the inverter. So the target of the voltage control loop is to keep power balance between the two outputs.

In this technique uses maximum power tracker. The maximum power tracker is a control loop in which the voltage control loop targets for balance between the DC and the AC output. The maximum power tracker goal is to operate the solar panels at a voltage level that permits maximum extraction of power [38], [39].

This method explains the DC offset controller: As the DC offset sensor is built from a double stage $\mathrm{RC}$ filter. The voltage across the ripple filter inductors $\left(v_{f}\right)$ is sensed and filtered. If the DC component in the inverter current was constant, the DC output voltage should be equal to IR, where R is the resistance of the two series connected inductors and I is the DC component of the current. This voltage known as $v_{0}$ in Figure 18. The filter output is fed to a proportional integral (PI) controller which has input reference equal to zero [38]. The controller output was putin such a way so as to cause $\mathrm{V}_{0}$ which is the mean value of $v_{0}$ to move down to zero. The integral action of the DC offset controller is to make sure that $\mathrm{V}_{0}$ is equal to zero at steady state. The DC offset controller needs some requirements to be carefully designed:

1. It should not get involved with the operation of the other control loops and vice versa.

2. Its dynamic response must be reasonable.

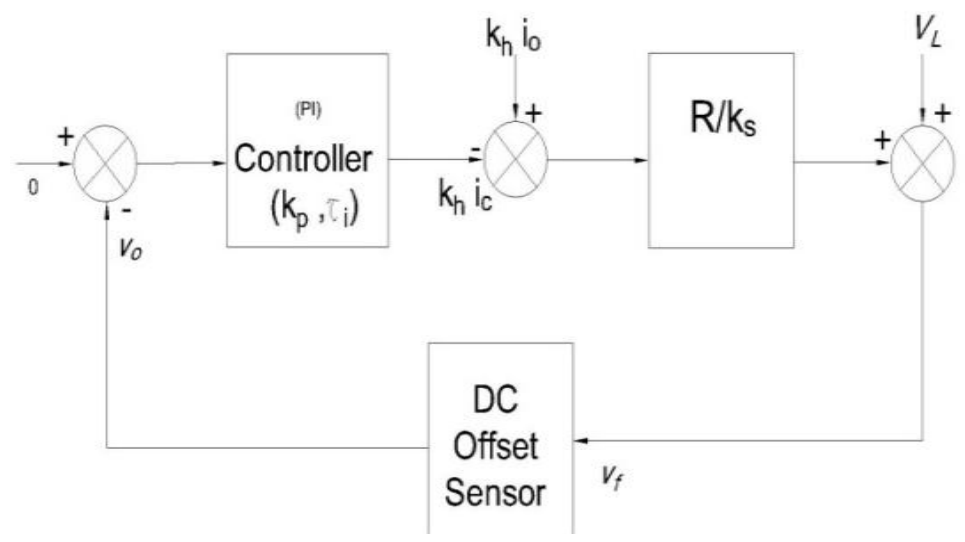

Figure 18. DC offset sensor block diagram

The designer of the DC offset sensor has to choose values for the parameters of that sensor to maintain the design requirements and specifications. Resistance $(\mathrm{R})$ could be just the inherent series resistance of the inductors. Although, it is found that this for resistance is too small the operation of the DC offset control loop, so additional resistance could be added but will lead to an increase in the power loss [38]. There are two main concepts for the DC offset controller:

1. Sufficiently damped output response.

2. The frequency component should reach the maximum value in its output signal.

The conclusion for this technique is that there is a simple feedback system has been presented to reduce the DC offset from the output of a single phase grid-connected inverter. DC offset get monitored by sensing the voltage across the ripple filter inductor. The DC signal is known by using the two stage RC filtering. The controller used is the PI controller which performs very satisfactorily and its components cost are very low. Although, when this technique is used practically there is small DC offset remains which lead us to found a better solution could have better results than that one. 


\section{NEW APPROACH USING DC LINK CURRENT SENSORS}

In grid connected photovoltaic applications, an output transformer is normally used to isolate the inverter from the supply. This transformer is heavy, costly and causes a huge power loss. However, the removal of output transformer causes unwanted DC components appearing in the inverter output current. There are different circuits can be used to substitute the output transformer through the grid connection. These circuits contain the 2-level half-bridge and the H-bridge inverters. However, these circuits have disadvantages such as the need for the high rated power devices. To get rid of these problems, the author proposed a technique that includes a three level half bridge inverter circuit is used, such that the DC-link voltage can be twice the device voltage rating to permit the use of low rated switching devices. This approach sets an auto calibrating DC link current sensing and control technique to monitor and calibrate the DC link current sensors used in the single phase 3-level half bridge inverter [40].

Grid connected inverters utilize current control with current sensors to impose unity power factor sinusoidal current into the grid [41]. the closed loop current control produces offset errors also including the current sensors and the analog to digital converter that suffer from DC offset and linearity errors [42]. The flow of the DC current through the distribution network can affect seriously the rotating machines and the distribution transformers. The transformer operating point can be shifted by small amount of DC current, which increases the RMS magnetizing current and causes additional winding losses [43], [44], [45]. This increase in the primary current leads to an overheat for the winding of the transformer and trip the input protection that leads to a reduction in the lifetime of the transformer [30].

The DC current which injected into the ground affects also the underground cable sheaths and pipelines (water and gas pipes) that are commonly used for grounding [46], [47]. DC current that flows through the buried conductors over a period of time can lead to serious problems with the earth due to corrosion of the conductor [44].

The use of an isolation transformer will lead to a small additional impedance because of the winding resistance of the transformer. Therefore, including this transformer will have a little impact on the tuning of the PI controller [48]. There are variety of types of current sensors available for power applications [49]. The principle of this operation has a big similarity with the method illustrated in section 7 that the circuit can be controlled to produce three output voltage states in three levels as presented in Table 1.

Table 1. Three level inverter output states

\begin{tabular}{cccccc}
\hline & & \multicolumn{4}{c}{ State of switching } \\
state & Output voltage & S1 & S2 & S3 & S4 \\
\hline 1 & $v_{d c} / 2$ & ON & ON & OFF & OFF \\
2 & 0 & OFF & ON & ON & OFF \\
3 & $-v_{d c} / 2$ & OFF & OFF & ON & ON \\
4 & 0 & OFF & ON & ON & OFF \\
\hline
\end{tabular}

During the connecting states which are state 1 and 3 the output current flows through the DC link current sensors to the load. During these states, the output current will be measured by the negative and the positive states DC link current sensors. While the freewheeling states which are state 2 and 4 , the output voltage across the inverter is zero and the freewheeling inductor current flows in one of the two loops, depending on the polarity of the previous connecting loop [40] and the circuit diagram as shown in Figure 6.

This approach presents results for the auto calibrating DC link current sensing technique applied to a three level half bridge inverter. The results confirm that the auto calibrating technique can compensate DC current offset for positive and negative DC link current sensors. The compensation is applied during the negative half cycle when the positive DC link current drops to zero and for the negative DC link sensor, in this case the compensation is applied during the positive half cycle when the negative DC link current drops to zero [40]. Therefore, the auto calibrating technique showed that there is a smaller offset error, and the experiments showed that the auto calibrating method when applied to a three level half bridge inverter can reduce the DC current injected to the grid. This approach could minimize the overall cost of the grid connected inverter by getting rid of the need of the transformer. So this method is better than that in section 7 as it has this auto calibrating scheme which can reduce the DC offset error instead of measuring discontinuous current as in section 7.

\section{DC CURRENT MEASUREMENT IN INVERTER OUTPUT}

This method that demonstrated by the author explains that it has been used shunt resistance to measure the DC current in inverter output [2], [11], [50]. There is a digital power meter on the other hand 
with the offset compensation strategy which switched on and off alternatively [13]. However, measuring DC current in the inverter output in other applications hasn't been proposed.

A current shunt resistor is one of the sensitive techniques used to measure AC or DC electrical currents in different applications, by using Ohm's law to measure the current after knowing the resistance of the shunt. This technique dose not suffer from linearity errors which seen in the hall effect sensor. It gives also non-inductive performance and high reliability. Although it has disadvantage which is the lack of galvanic isolation between the measurement circuit and the power circuit. The shunt is also a source of power loss $\left(\mathrm{I}^{2} \mathrm{R}_{\text {shunt }}\right)$ where $\mathrm{R}_{\text {shunt }}$ is the value of the shunt resistance and $\mathrm{I}$ is the current passes through the shunt resistance [51]. Figure 19 shows the connection of the shunt resistance as a measured device.

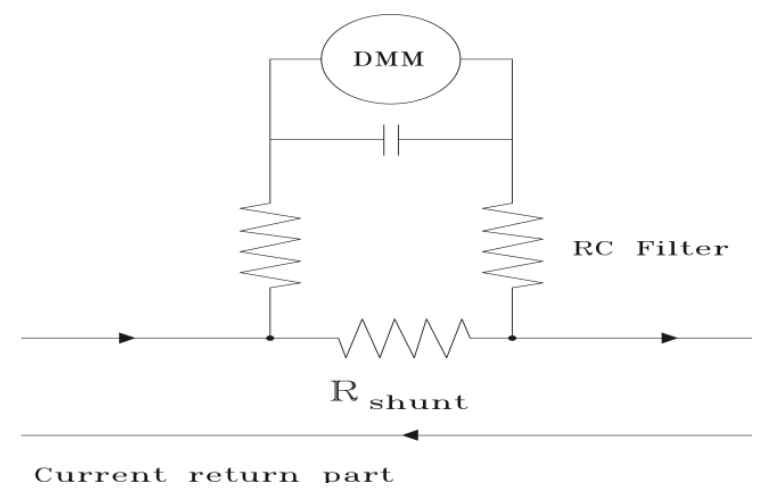

Figure 19. Shunt resistor method for current measurement

The lower values for resistance are chosen (such as $0.50 \mathrm{~m} \Omega$ ), the more losses can be minimized [52], especially in grid connected inverters. The smaller value of the shunt resistor leads to a smaller voltage appears across the shunt. This will affect the measurement accuracy and resolution, because of noise levels which in some cases become greater than the measured signal. For this case, a high common mode rejection shunt amplifier is needed to reduce the unwanted noise and gets a pure signal.

This technique is achieved by connecting a series shunt resistance in the inverter output between the AC filter and the load. The voltage across the shunt passes through RC low pass filter(LPF) with a cut off frequency $1 \mathrm{~Hz}$ to reject the $50 \mathrm{~Hz} \mathrm{AC}$ component as the author designed. The possibility of common mode leakage is eliminated which affects the accuracy, a battery-operated Digital Multi-Meter(DMM) is used to measure the DC voltage. The DC voltage measured by the DMM is scaled by the shunt resistance value to identify the DC current component in the inverter output.

\section{A NOVEL CONTROL STRATEGY}

The authors propose in this method a new technique such that the photovoltaic (PV) inverters become more applicable because of the lower weight and the higher efficiency. Although it may have DC offset current problem. So the authors propose a novel control strategy of suppressing DC current injection to the grid for PV inverters. This method based on the idea of accurately sensing the DC offset voltage of PV inverter output, such that the DC component of the inverter output can be eliminated and the DC injection to the grid can be reduced effectively [53].

Photovoltaic inverters without isolation transformers become more attractive in grid connected PV systems due to higher efficiency and smaller size [54], [55], [56], [57]. Although, they are unable to eliminate DC current injection [58]. That may lead to saturation of distribution transformer in the grid and results in overheating in power system, higher loss, and poor power quality [54], [59]. Therefore, there are regulations and standards have been introduced to suppress PV inverter DC injection to the grid [33], [60].

For eliminating DC injection, the authors proposed some control methods [61], [62]. The techniques for DC current injection elimination can e classified mainly into four categories: novel inverter topology with DC current elimination ability, blocking DC current with the capacitor, voltage detection control and current detection control. The technique of blocking DC current with the capacitor uses a capacitor connected serially between the grid and the inverter [61].

The authors propose this novel strategy by showing the full bridge PV inverter without output isolation transformer as shown in Figure 20, where $I_{\text {ref }}$ is the amplitude of the grid current command and $\theta$ is the phase angle of grid current which is synchronized with grid voltage by phase locked loop. 


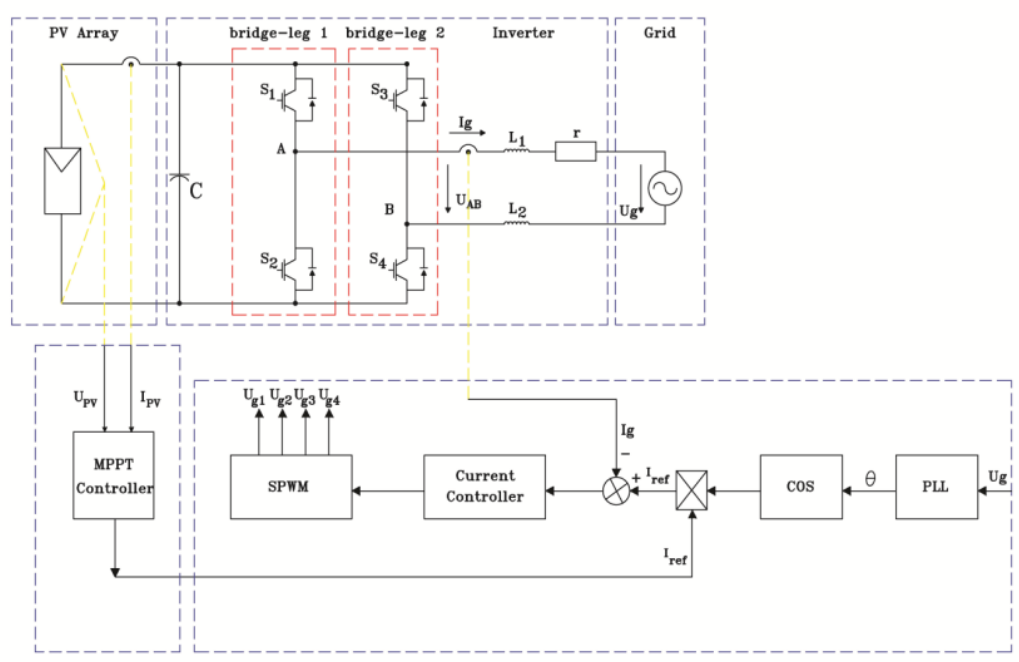

Figure 20. Original scheme diagram of PV grid connected inverter

PV inverter output has DC offset voltage component generally which can be obtained from disparity of power modules, detection of current errors, etc. Traditionally, there is a transformer is placed between the PV inverter and the grid. However, the output of the PV inverter may have DC voltage component, there is no DC current injection to the grid. Although, in the case of the PV inverter without isolation transformer, the inverter output DC offset may lead to a significant DC current injection to the grid, which could cause a disturbance for grid connection standards [63]. In order to restrain effectively DC current injection to the grid, a control strategy for a single phase PV inverter without the isolation transformer is shown in Figure $21[64]$.

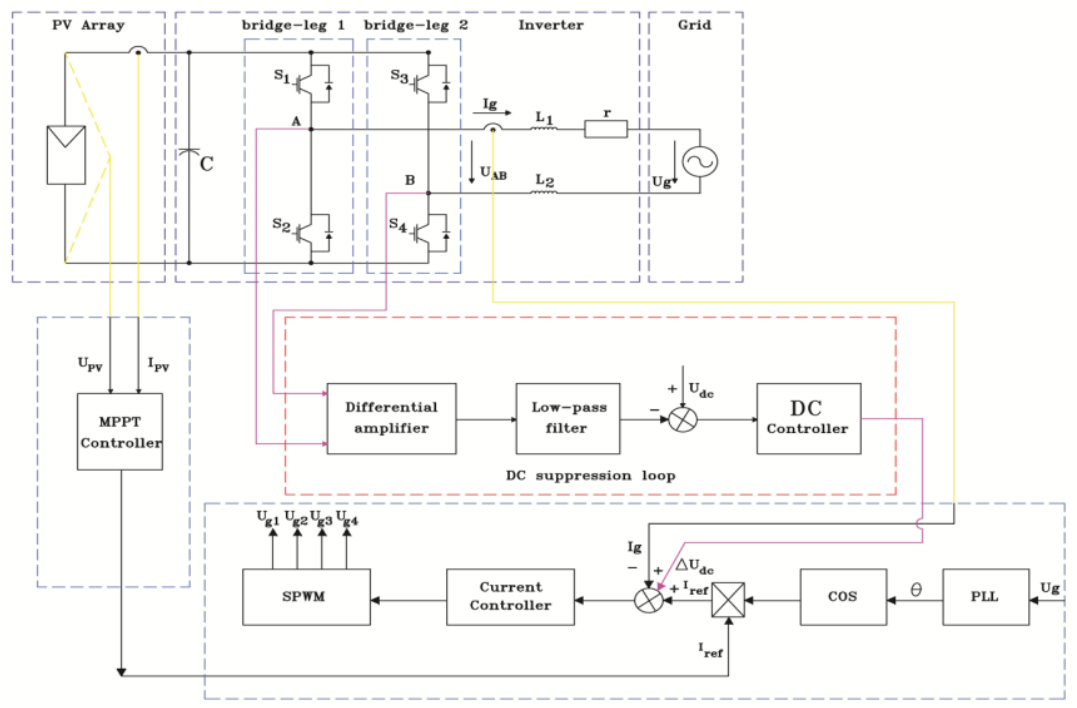

Figure 21. Original scheme diagram of PV grid connected inverter

Compared with Figure. 1, an extra dc offset voltage suppression loop is added to the previous control scheme. The de suppression loop is composed of a DC controller, low pass filter, and differential amplifier. The novel control strategy has two main features. The first one is that the differential amplifier is used to sample the DC offset voltage between the two bridge-leg middle points of full bridge inverter. To detect accurately the dc offset voltage of the inverter switch-side output voltage $\mathrm{u}_{\mathrm{AB}}$, a high-precision 
differential amplifier with low offset and high common-mode rejection ratio is needed. The using of differential amplifier can not only reduce the cost, but also avoid the zero-drift by using Hall-effect sensors. The second one is that dc suppression loop can suppress inverter output disturbances. Therefore, the DC current injected to the grid can be effectively suppressed.

\section{TRANSFORMERLESS METHOD}

Presents a considerable technique to detect DC current injection into the grid that can be used with any connected inverters to the grid with small area as delineated in Figure. 19. The main advantage of this procedure is that it doesn't depend on any high current measurement tools and get rid of using any expensive transformers. So it gives space for work in any operation without using transformer for all inverters. One inverter can make DC offset compensation in addition to power interfacing into the grid. The transformer saturation can be neglected through using the inverter for compensation of the DC offsets that may appear. This technique forces DC offset to become zero using proportional integral controller. The proportional integral controller expects the DC components wanted in the modulation signal of every phase to calculate DC offsets in the total current [65].

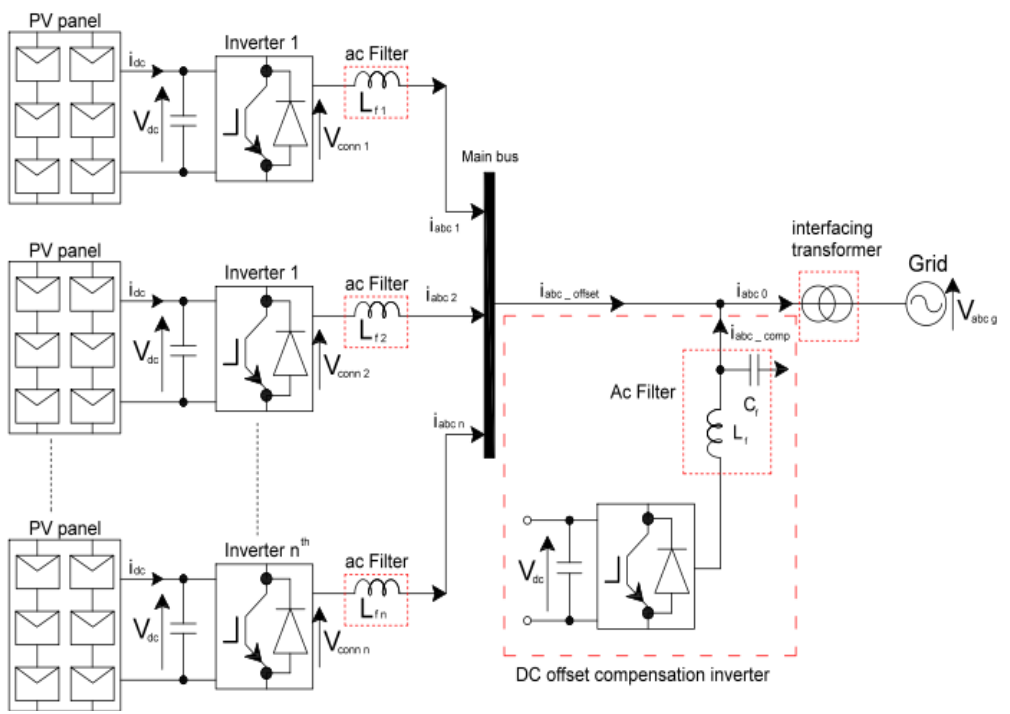

Figure 19. Diagram for grid connected inverters with DC offset compensation inverter

\section{CONCLUSION}

This paper gives a brief about number of solutions for eliminating the DC offset as minimum as possible. Some of these solutions are cost effective, others use high current measurement tools. There is a solution use a DC offset current sensor, another one use transformer and that costs too much. There is a solution which give good results but theoretically only as there is no experimentation validate this solution or this technique as well. In sequence there are better solutions used without any complex transformer, so it gives space for work in any operation without using transformer for all inverters. This paper was made to know all the solutions and to find which is the most appropriate solution to deal with and work on it in any other research and how to be improved.

\section{REFERENCES}

[1] T.L. Ahfock ${ }^{1}$, L. Bowtell ${ }^{2}$, "DC offset elimination in a single-phase grid-connected photovoltaic system," presented at the AUPEC 2006: 16th Australasian Universities Power Engineering Conference, Melbourne, Australia, 2006.

[2] M. Armstrong ${ }^{1}$, D. J. Atkinson ${ }^{2}$, C. M. Johnson ${ }^{3}$, and T. D. Abeyasekera ${ }^{4}$, "Auto-Calibrating DC Link Current Sensing Technique for Transformerless, Grid Connected, H-Bridge Inverter Systems, " Power Electronics, IEEE Transactions on, vol. 21, pp. 1385-1393, 2006.

[3] G. Buticchi ${ }^{1}$, E. Lorenzani ${ }^{2}$, and G. Franceschini ${ }^{3}$, "A DC Offset Current Compensation Strategy in Transformerless Grid-Connected Power Converters," Power Delivery, IEEE Transactions on, vol. 26, pp. 27432751, 2011. 
[4] E.N. Association, "Recommendations for the connection of small-scale embedded generators (up to 16 A per phase) in parallel with public low-voltage distribution networks, Engineering Recommendation G83/1, UK, " ed, 2003.

[5] IEEE Recommended Practice for Utility Interface of Photovoltaic (PV) Systems, "IEEE Std 929-2000, p. i, 2000.

[6] T. A. Standard, "AS4777.2-2005 Grid Connection of Energy Systems via Inverters- Inverter Requirements, "ed, 2005.

[7] M. Calais1, V. G. Agelidis2, and M. S. Dymond3, "A Cascaded inverter for transformerless single-phase gridconnected photovoltaic systems," Renewable Energy, vol.22, pp. 255-262, 2001

[8] T. Kerekes1, R. Teodorescu2, P. Rodriguez3, G. Vazquez4, and E. Aldabas5, " A new High-Efficiency SinglePhase Transformerless PV Inverter Topology," Industrial Electronics, IEEE Transactions on, vol. 58, pp. 184$191,2011$.

[9] H. Haeberlin, "Evolution of Inverters for Grid connected PV-Systems from 1989 to 2000, "measurement, vol. 2, p. $1,2001$.

[10] F. Berba1, D. Atkinson2, and M. Armstrong3, "A review of minimization of output DC current component methods in single-phase grid-connected inverters PV applications, " in Environment Friendly Energies and Applications (EFEA), 2012 2nd International Symposium on, pp.296-301, 2012.

[11] W.M. Blewitt1, D. J. Atkinson2, J. Kelly3, and R. A. Lakin4, "Approach to low-cost prevention of DC injection in transformerless grid connected inverters, " Power Electronics, IET, vol. 3, pp. 111-119, 2010.

[12] L. A. Bowtell1 and A.L. Ahfock2, "Dynamic analysis of a DC offset controller for grid-connected inverters, " in Universities Power Engineering Conference (AUPEC), 2010 20TH Australasian, pp.1-5, 2010.

[13] G. Buticchi1, G. Franceschini2, E. Lorenzani3, C. Tassoni4, and A. Bellini5, "A novel current sensing DC offset compensation strategy in transformerless grid connected power converters, " in Energy Conversion Congress and Exposition, 2009. ECCE2009. IEEE, , pp. 3889-3894, 2009.

[14] Tony Ahfock ${ }^{1}$, and Leslie Bowtell ${ }^{2}$, "DC Offset Elimination in a Single Phase Grid-Connected Photovoltaic System, " Australian Standard AS 4777.2, 2005.

[15] Jungeui Park ${ }^{1}$, Jungsoo Choi ${ }^{2}$, Wooju Jeong ${ }^{3}$, Sanduk Yu ${ }^{4}$, Kichang Jang ${ }^{5}$, Youngchan Choi ${ }^{6}$, and Joongho Choi ${ }^{7}$, "Current-Sensing Technique for Current-Mode DC-DC Buck Converter with Offset-Voltage Compensation," IEEE, 2008.

[16] K. Onizuka, K. Inagaki, H. Kawaguchi, M. Takamiya, and T. Sakurai, "Stacked-Chip Implementation of On-Chip Buck Converter for Distributed Power Supply System in SiPs, "IEEE J. Solid-State Circuit, vol.42, no.11m pp. 2404-2410, Nov.2007.

[17] G. Patounakis, Y. W. Li, and K. L. Shepard, " A Fully Integrated On-Chip DC-DC Conversion and Power Management System, "IEEE J. Solid-State Circuit, vol.39, no.3, pp. 443-451, Mar. 2004.

[18] H. Lhermet, C.Condemine, M. Plissonnier, R. Salot, P. Audelbert, and M. Rosset, "Efficient Power Management Circuit: From Thermal Energy Harvesting to Above-IC Microbattery Energy Storage," IEEE J. Solid-State Circuit, vol.43, no.1, pp. 246-255, Jan.2008.

[19] Chnlei Shi, B. C. Walker, E. Zeisel, B. Hu, and G.H. McAllister,"A Highly Integrated Power Management IC for Advanced Mobile Application, " IEEE J. Solid-State Circuit, vol.42, no.8, pp. 1723-1731, Aug. 2007.

[20] Kwok-Wai Ma and Yim-Shu Lee, "Technique for sensing inductor and DC output currents of PWM DC-DC converter," IEEE Trans. Power Electron., vol. 9, no. 3, pp. 346-354, May 1994.

[21] Cheung Fai Lee amdMok, P.K.T., "An integrated CMOS current sensing circuit for low-voltage current-mode buck regulator," IEEE Transactions on Circuits and Systems II, vol.52, no. 7, pp.394-397, July 2005.

[22] Hong-Wei Huang, Ke-Horng Chen, and Sy-Yen Kuo, "Dithering Skip Modulation, Width and Dead Time Controllers in Highly Efficient DC-DC Converters for System-On-Chip Applications, " IEEE J. Solid-State Circuit, vol.42, no.11, pp. 2451-2465, Nov.2007.

[23] Stephen Shang, ShahriarMirabbasi, and ResveSaleh, "A Technique for DC-Offset Removal and Carrier Phase Error Compensation in Integrated Wireless Receivers" IEEE, March 2003.

[24] B. Razavi, "Design Considerations for Direct-Conversion Receivers," IEEE Trans on Circuits and Systems II, vol. 44, no. 6, pp.428-35, June 1997.

[25] S. Mirabbasi and K. Martin, "Classical and Modern Receiver Architectures, " IEEE Commun. Mag., pp.132-139, Nov.2000.

[26] W. Namgoong and T.H. Meng, "Direct-Conversion RF Receiver Design," IEEE Trans. on Communications, vol.49, no.3, pp.518-529, March 2001.

[27] Swathi Marri, Jaime Ramirez-Angulo, Antonio J. Lopez-Martin, and Ramon G. Carvajal, "A new scheme for DC offset compensation and its application to current mode and voltage mode D/A converters" IEEE, September 2009.

[28] BehzadRazavi, Design of Analog CMOS Integrated Circuits, Tata McGraw-Hill, pp.424-439, 2002.

[29] Masoud K., Ledwich G., " Grid connection without mains transformers', Electr. Electron. Eng., pp. 31-36, 1999.

[30] Ahfock A., Hewitta.: "DC magnetization of transformers", IEE Proc. Electr. Power Appl., pp. 601-607, 2006.

[31] Bradly S., Crabtree J.: "Effects of DC from embedded generation on residual current devices and single-phase metering". EA technology report no. WS4-P11, 2005.

[32] Salas V., Olias E., Alonso M., Chenlo F.: 'Overview of the legislation of DC injection in the network for low voltage small grid-connected PV systems in Spain and other countries', Renew. Sustain. Rev., pp. 575-583, 2008.

[33] "Recommendations for the connection of small-scale embedded generators (up to 16 A per phase) in parallel with public low-voltage distribution networks", United Kingdom, June 2008. 
[34] Haeberlin H., Liebi CH., Beutler CH.:" Inverters for grid connected PV systems: test results of some new inverters and latest reliability data of most popular inverters in Switzerland". 14th European Photovoltaic Solar Energy Conf., Barcelona (Catalunya), Spain, June/July 1997.

[35] Salas V., Olias E., Alonso M., Chenlo F., Barrado V.:"DC current injection into the network from PV grid inverters". IEEE Fourth World Conf. on Photovoltaic Energy Conversion, pp. 2371-2374, May 2006.

[36] Calais M., Myrzik J., Spooner T., Agelidis V.G.: 'Inverters for single-phase grid connected photovoltaic systems an overview'. IEEE 33rd Ann. Power Electronics Specialists Conf., pp. 1995-2000, vol. 4, 2002.

[37] Law C.M., Chen T.H., Wang T.C., Cho G.J., Lee C.M., Wang C.T.: "Design and implementation of a single phase current forced switching mode bilateral convertor", pp. 129-136 IEE Proc. B, 1991.

[38] L.Bowtell, and A. Ahfock. :"Direct current offset controller for transformerless single-phase photovoltaic gridconnected inverters." Faculty of Engineering and surveying, University of Southern Queensland, Queensland, Australia, April 2010.

[39] Azevedo G.M.S., Cavalcanti M.C., Oliveira K.C., Neves F.A.S., Linsz. D.: "Comparative evaluation of maximum power point tracking methods for photovoltaic systems, American Society of Mechanical Engineering", J.Solar Energy Eng. 131, article id 031006, pp. 1-8, 2009.

[40] Farag Berba, David Atkinson, and Matthew Armstrong, " A New approach of Prevention of DC Current Component in Transformerless Grid-Connected PV Inverter Application" IEEE, 2014.

[41] S. B. Kjaer, J. K. Pedersen, and F. Blaabjerg, "A review of single-phase grid-connected inverters for photovoltaic modules, " Industry Applications, IEEE Transactions on, vol. 41, pp. 1292-1306,2005.

[42] L. Cristaldi, A. Ferrero, M. Lazzaroni, and R. T. Ottoboni, "A linearization method for commercial Hall-effect current transducers, "Instrumentation and Measurement, IEEE Transactions on, vol. 50, pp.1149-1153, 2001.

[43] L. Gertmar, P. Karlsson, and O. Samuelsson, "On DC injection to AC grids from distributed generation, " in Power Electronics and Applications, 2005 European Conference on, 2005, pp. 10 pp.-P. I0.

[44] [A. E. Emanuel, D. 1. Pileggi, and F. 1. Levitsky, "Direct Current Generation in Single-Phase Residential Systems DC Effects and Permissible Levels, " Power Apparatus and Systems, IEEE Transactions on, vol. PAS-1 03, pp. 2051-2057, 1984.

[45] A. Kitamura, F. Yamamoto, H. Matsuda, K. Akhmad, and Y.Hamakawa, "Test results on DC injection phenomenon of grid connected PV system at Rokko test center, " in Photovoltaic Specialists Conference, 1996. Conference Record of the Twenty Fifth IEEE, 1996, pp. 1377-1379.

[46] [P. J. Lagace, J. L. Houle, H. Greiss, and D. Mukhedkar, "Computer aided evaluation of pipeline current near toroidal HVDC ground electrodes, " Power Delivery, IEEE Transactions on, vol. 4, pp. 216222, 1989.

[47] U. o. Strathclyde, "DC injection into low voltage AC networks, DTl commissioned report," June 2005.

[48] "Isolated current and voltage transducers Characteristics - Applications- Calculations ", LEM, Applications Guide, available at [www. lem.com]".

[49] F. Costa, P. Poulichet, F. Mazaleyrat, and E. Laboure, "The current sensors in power electronics, a review, " EPE JOURNAL, vol. 1, pp. 718,2001.

[50] F. Berba, D. Atkinson, and M. Armstrong, "Minimization of DC current component in transformerless Gridconnected PV inverter application," in Environment and Electrical Engineering (EEEiC),2011 iOth international Conference on, 2011, pp. 1-4.

[51] S. Ziegler, R. C. Woodward, H. H. C. lu, and L. J. Borle, "Current Sensing Techniques: A Review," Sensors Journal, IEEE, vol. 9, pp.354-376,2009.

[52] Precision Current Sense Resistors, TGHG Series, Applications Guide, available at[www.ohmite.com].

[53] Guofeng He, Dehong Xu, Fellow, and Min Chen "A Novel Control Strategy of Suppressing DC Current Injection to The Grid for Single-Phase PV Inverter" IEEE transactions on power electronics, vol.30. no.3.march 2015.

[54] R. Gonzalez, E. Gubia, J. Lopez, and L. Marroyo, "Transformerless single-phase multilevel-based photovoltaic inverter,” IEEE Trans. Ind. Electron., vol. 55, no. 7, pp. 2694-2702, Jul. 2008.

[55] J. M. Carrasco, L. G. Franquelo, J. T. Bialasiewicz, E. Galvan,R. C. Portillo Guisado, M. A. MParts, J. I. Le'on, and N. Moreno-Alfonso,"Power-electronic systems for the grid integration of renewable energy sources: A survey," IEEE Trans. Ind. Electron., vol. 53, no. 4, pp. 1002-1016, Jun. 2006.

[56] B. Yang, W. Li, Y. Gu, W. Cui, and X. He, "Improved transformerless inverter with common-mode leakage current elimination for a photovoltaic grid-connected power system," IEEE Trans. Power Electron., vol. 27, no. 2, pp. 752 762, Feb. 2012.

[57] [J. Lee and K. Lee, "New modulation techniques for a leakage current reduction and a neutral-point voltage balance in transformerless photovoltaic systems using a three-level inverter," IEEE Trans. Power Electron., vol. 29, no. 4, pp. 1720-1732, Apr. 2014.

[58] D. G. Infield, P. Onions, A. D. Simmons, and G. A. Smith, "Power quality from multiple grid-connected singlephase inverters," IEEE Trans. Power Del., vol. 19, no. 4, pp. 1983-1989, Oct. 2004.

[59] S. B. Kjaer, J. K. Pedersen, and F. Blaabjerg, "A review of single-phase grid-connected inverters for photovoltaic modules," IEEE Trans. Ind. Appl., vol. 41, no. 5, pp. 1292-1306, Sep. 2005.

[60] AS 4777.2, Grid connection of energy system via inverters. Part 2: Inverter requirements Australia, 2002.

[61] R. Gonzalez, J. L'opez, P. Sanchis, and L. Marroyo, "Transformerless inverter for single-phase photovoltaic systems," IEEE Trans. Power Electron.,vol. 22, no. 2, pp. 693-697, Mar. 2007.

[62] G. He and D. Xu, "A novel DC loop current control strategy for paralleled UPS inverter system based on decoupled control scheme," in Proc. Int. Symp. Ind. Electron., Hangzhou, China, May 28-31, 2012, pp. 70-75.

[63] Wei. Yu, "Key issues research on paralleled UPS systems," Ph.D. dis-sertation, College Electr. Eng., Zhejiang University, Hangzhou, Zhejiang, China, 2009. 
[64] G. He, M. Chen, N. Su, R. Xie, and D. Xu, "A novel control strategy to suppress DC current injection of singlephase PV inverter to the grid," presented at the IEEE Power Electronics for Distributed Generation Systems Conference, Rogers, AR, USA, Jul. 8-11, 2013.

[65] S.A. Azmi ${ }^{1}$, M.A. Roslan ${ }^{2}$, G.P. Adam ${ }^{3}$ and B.W. Williams ${ }^{4}$, "DC Current Offset Compensation Technique in Grid Connected Inverters," $9^{\text {th }}$ International Conference on Power Electronics-ECCE Asia63 Convention Center, Seoul, Korea June 1-5, 2015. 